This is the peer reviewed version of the following article: De Clercq, Dirk, Haq, Inam Ul, Azeem, Muhammad Umer and Hassan, Amna (2020) How career plateau beliefs and leader interpersonal unfairness harm job performance in dysfunctional organizational settings. Canadian Journal of Administrative Sciences, 37(3), pp. 197-210, which has been published in final form at https://doi.org/10.1002/cjas.1560. This article may be used for non-commercial purposes in accordance with Wiley Terms and Conditions for Use of Self-Archived Versions 
How career plateau beliefs and leader interpersonal unfairness harm job performance in dysfunctional organizational settings

\author{
Dirk De Clercq \\ Inam Ul Haq \\ Muhammad Umer Azeem
}

Amna Hassan

Paper accepted for Canadian Journal of Administrative Sciences 


\title{
How career plateau beliefs and leader interpersonal unfairness harm job performance in political organizational settings
}

\begin{abstract}
Building on social exchange theory and attribution theory, this study unpacks the relationship between employees' perceptions of organizational politics and job performance, considering the mediating effect of career plateau beliefs and the moderating effect of leader interpersonal unfairness. The findings provide empirical support for the theoretical predictions. An important reason that perceptions of dysfunctional organizational politics reduce job performance is that employees develop beliefs that opportunities for their career development are limited. This mediating role of career plateau beliefs is particularly salient to the extent that employees are exposed to organizational leaders who treat them with disrespect. Organizations can mitigate the risk that highly politicized decision-making processes lead to negative performance outcomes by stimulating fair interpersonal relationships.
\end{abstract}

Keywords: organizational politics, career plateau, job performance, leader interpersonal unfairness, social exchange theory, attribution theory 


\section{Introduction}

Employees' perceptions that their organization's decision-making processes are guided by dysfunctional political games represents a significant concern, because this adverse work condition can harm their mental well-being and the quality of their organizational functioning (Chang, Rosen, \& Levy, 2009; Johnson, Rogers, Stewart, David, \& Witt, 2017). Notably, such a political climate undermines the exchange expectations that employees have in terms of how their organization should treat them (Chang, Rosen, Siemieniec, \& Johnson, 2012), which might become manifest in various ways, such as when employees believe that favoritism supersedes merit, a limited number of organizational members always get their way, their employer endorses a work-behind-the-scenes mentality, or people do not dare speak for fear of retaliation (De Clercq \& Belausteguigoitia, 2017; Kacmar \& Ferris, 1991). The harmful character of such organizational politics has received burgeoning interest in academic research, and its persistence and the threat it invokes in terms of undermining employee morale and performance make it a central point of interest for continued investigation in various settings, including non-Western contexts (Abbas, Raja, Darr, \& Bouckenooghe, 2014; Jam, Donia, Raja, \& Ling, 2017).

Employees might make sense of and accept some level of organizational politics or even assign them some positive connotations (e.g., opportunities to leverage their own political skills; Brouer, Harris, \& Kacmar, 2011), but the theoretical focus for the current research is on employees' perceptions of a dysfunctional organizational climate that endorses self-serving behaviors and gives precedence to individual interests at the expense of the collective good (Abbas et al., 2014; Kacmar \& Ferris, 1991). The self-serving behaviors that mark dysfunctional organizational politics can lead to various detrimental outcomes, such as heightened stress levels (Jam et al., 2017) and turnover intentions (Poon, 2003) or diminished innovation outcomes 
(Parker, Dipboye, \& Jackson, 1995) and extra-role citizenship behaviors (De Clercq \& Belausteguigoitia, 2017).

Prior research also indicates a negative and significant relationship between employees' perceptions of organizational politics and their ability to meet their in-role performance requirements (Abbas et al., 2014; Rosen, Harris, \& Kacmar, 2011), a relationship that might be clarified by mediating mechanisms such as higher job strain or lower work motivation and organizational commitment (Chang et al., 2009; Siu, Lu, \& Spector, 2013; Yen, 2015). To add to this research stream, we consider an unexplored causal mechanism that might underpin the relationship between perceptions of organizational politics and job performance, namely, employees' beliefs that they have reached a career plateau (Foster, Lonial, \& Shastri, 2011). This concept captures the extent to which the organization offers limited opportunities for employees' professional development and growth (Chao, 1990; Lee, 2003). Our focus is specifically on beliefs about the presence of a career plateau, consistent with the argument that "the subjective evaluation of future career development is the appropriate focal point because it emphasizes how the individual perceives, assesses, and reacts to the present work situation" (Tremblay \& Roger, 1993, p. 412). That is, it is employees' perceptions of limited career possibilities, not the actual reality, that drives their work attitudes and behaviors (Chao, 1990; Foster, Shastri, \& Withane, 2004). When employees develop strong career plateau beliefs, they feel frustrated and disappointed with their career advancement (Lemire, Saba, \& Gagnon 1999; Rotondo \& Perrewé, 2000), which can generate negative outcomes, including higher absenteeism, withdrawal (Conner, 2014), and turnover intentions (Rotondo \& Perrewé, 2000; Tremblay, Roger, \& Toulouse, 1995), as well as lower job satisfaction, organizational identification (Chao, 1990), job performance, and productivity (Appelbaum 1994; Conner, 
2014). Employees' sense that their career has reached a plateau represents a critical challenge for many organizations, and it accordingly is of paramount importance to understand the drivers and outcomes of such beliefs (Lim \& Teo, 1998; Lin, Chen, \& Lai, 2018; Tremblay et al., 1993; Yang, Johnson, \& Niven, 2018).

In addition to proposing that perceptions of organizational politics might undermine job performance because employees believe that their organization offers limited opportunities for their career development (Chao, 1990; Lee, 2003), we argue that the causal mechanism resulting from career plateau beliefs might be activated by the extent to which employees confront disrespectful treatment from their immediate supervisors (Flint, Haley, \& McNally, 2013; Yang, Johnson, Zhang, Spector, \& Xu, 2013). Such leader interpersonal unfairness is a critical dimension of the wider concept of organizational unfairness or injustice, which also includes distributive unfairness (outcome-oriented comparison of inputs and outputs), procedural unfairness (process-oriented assessment of policies and procedures), and informational unfairness (inadequate information provision) (Colquitt, Conlon, Wesson, Parter, \& Ng, 2001; Judge \& Colquitt, 2004). However, we explicitly focus on the interpersonal dimension, in line with evidence that this dimension has the strongest link with the quality of the exchange relationship between employees and their supervisors, whereas the other dimensions are more pertinent to their relationship with the employing organization overall (Cropanzano, Prehar, \& Chen, 2002; Kulkarni \& Ramamoorthy, 2017). By integrating leader interpersonal unfairness with perceived organizational politics in our model, we also acknowledge that employees enter into two critical exchange relationships at work: with their organization in general and with the person to whom they report (Flint et al., 2013; Masterson, Lewis, Goldman, \& Taylor, 2000). 
To anchor these conceptual arguments about the indirect effect of perceptions of organizational politics on job performance through career plateau beliefs, along with the invigorating role of leader interpersonal unfairness, we draw primarily from social exchange theory. According to this theory, organizations are places in which employees contribute their time and efforts in exchange for organizational rewards, which include salaries and other monetary rewards but also prospects for personal growth and career development (Blau, 1964; Emerson, 1976). When an organizational climate is marked by dysfunctional political dynamics, employees may sense that their work contributions are not fully recognized, because rewards tend to be based on favoritism and nepotism rather than merit (Chang et al., 2012; Rusbult, Campbell, \& Price, 1990). That is, they tend to see only a weak connection between their work efforts and desirable career outcomes (Chang et al., 2012; Kacmar \& Baron, 1999), so this manifestation of poor organizational support may trigger them to express frustration about their limited career prospects (Cao, Hirschi, \& Deller, 2014; Tremlay \& Roger, 1993) and ultimately to reject performance-enhancing work activities (Conner, 2014).

We also draw from attribution theory to substantiate the potentially positive relationship between perceived organizational politics and career plateau beliefs. That is, adverse work conditions may steer employees to attribute anticipated work challenges—resulting from dysfunctional political games in our study context—to the organization's general lack of support for their career-related well-being (Schroth \& Shah, 2000; Zuckerman, 1979). Attribution theory complements social exchange theory by explicating that employees may blame their organization for insufficient career opportunities if they believe their organizational functioning is hampered by dysfunctional political games, which enables them to avoid responsibility for potential personal failures in this situation (De Clercq, Haq, \& Azeem, 2018; Zuckerman, 1979). 
The logic of social exchange theory also suggests that employees' negative reactions to dysfunctional political climates may escalate when they suffer from adverse exchange relationships with their immediate supervisor (Flint et al., 2013; Li, Xu, Tu, \& Lu, 2014). That is, frustration with self-serving tendencies in organizational decision-making processes may grow stronger to the extent that employees lack supportive exchange relationships with their organizational leaders (Yang et al., 2013). Formally, we propose that employees' exposure to leader interpersonal unfairness functions as a catalyst of their beliefs about the presence of a career plateau (Chao, 1990; Foster et al., 2011), which arise from their perceptions of organizational politics, and that it in turn diminishes the likelihood that they are willing to devote significant energy to performance-enhancing activities (Conner, 2014; Quinn, Spreitzer, \& Lam, 2012).

\section{Contributions}

With this study, we seek to make several contributions. First, we leverage social exchange theory to investigate how employees' perceptions of organizational politics might lead to poorer job performance, due to their beliefs about constrained opportunities for further career development (Foster et al., 2011; Tremblay et al., 1995). Such career plateau beliefs may function as important outcomes of employees' perceptions that their employer has not met its exchange obligations toward them, because it endorses a self-serving culture of favoritism (Blau, 1964; Chang et al., 2009; Kacmar \& Baron, 1999). In turn, these beliefs may reduce employees' propensity to allocate their personal energy to performance-enhancing activities, as a form of retaliation (Blau, 1964; Chang et al., 2012; Nachbagauer \& Riedl, 2002). The sense that they have reached a career plateau — a pertinent organizational concern that surprisingly has received relatively little research attention (Conner, 2014; Foster et al., 2011; Lin et al., 2018)—represents 
an understudied mechanism by which employees' perceptions of organizational politics may thwart their performance.

Second, we consider when this translation of perceptions of organizational politics into reduced job performance, through career plateau beliefs, might be more likely to materialize. In particular, employees' exposure to disrespectful leaders who exhibit interpersonal unfairness (Yang et al., 2013) might invigorate the harmful effect of a dysfunctional political climate on beliefs about a stalled career path, as well as reinforce the escalation of those beliefs into a reduced propensity to engage in performance-enhancing activities. Negative exchange dynamics in the relationship with supervisors can affirm employees' fear that there is no future for them in an organizational climate that already is marked by unfair decision-making processes (Flint et al., 2013; Yang, Mossholder, \& Peng, 2009), which increases their frustrations about the presence of limited opportunities for career development (Tremblay \& Roger, 1993) and thwarts their job performance (Conner, 2014). By noting this potential invigorating role of leader interpersonal unfairness, we complement studies that indicate moderating influences of other sources of relational adversity on the negative effects of dysfunctional organizational politics, such as low quality leader-member exchange relationships (Rosen et al., 2011) or a lack of trust in top management (Bouckenooghe, 2012). Moreover, our focus on the moderating role of leader interpersonal unfairness adds to research that considers the direct harmful effect of this negative relational feature on outcomes such as turnover intentions (Flint et al., 2013) or counterproductive work behaviors (Yang et al., 2013).

Third, we focus on Pakistan as our study context, in response to calls for more research on the negative roles of dysfunctional organizational politics in non-Western settings (Abbas et al., 2014; Jam et al., 2017). Pakistan offers an interesting setting, because its cultural 
characteristics invoke two opposing forces relevant to our conceptual model. On the one hand, its high collectivism implies that decision-making processes might be driven by a tendency to grant favors to members of an inner circle, at the expense of out-group members (Hofstede, Hofstede, \& Minkov, 2010). Its high power distance also implies that it may be relatively common for organizational leaders to treat followers with little respect or dignity (Khan, Moss, Quratulain, \& Hameed, 2016). The presence of organizational politics and leader interpersonal unfairness thus might be prevalent, such that employees may have grown somewhat immune to these negative aspects of their work context (Khan, Quratulain, \& Crawshaw, 2017). On the other hand, Pakistan features high levels of uncertainty avoidance (Hofstede et al., 2010), so employees in this country may feel especially stressed and uncomfortable in adverse work situations, such as when organizational decision making is unpredictable, based on favoritism and a behind-thescenes mentality, or when they are treated disrespectfully by organizational leaders. In light of these opposing forces, Pakistan offers a compelling context for investigating our focal research issues, with potential implications for countries with similar cultural profiles.

\section{Conceptual model}

We summarize our proposed conceptual model in Figure 1, in which we theorize that perceptions of organizational politics spur career plateau beliefs, which diminish job performance. Negative beliefs about limited opportunities for career development thus mediate between perceptions of organizational politics and job performance. Leader interpersonal unfairness triggers this process, such that the translation of perceptions of organizational politics into reduced job performance, through career plateau beliefs, is more likely when employees are unfairly treated by organizational leaders.

\footnotetext{
[Insert Figure 1 about here]
} 


\section{Hypotheses}

\section{Mediating role of career plateau beliefs}

We hypothesize a positive relationship between employees' perceptions of organizational politics and their career plateau beliefs. Social exchange theory underscores how employees' work attitudes and behaviors are driven by the extent to which their organization meets its obligations toward them, such as by acknowledging their work efforts or caring about their career success (Emerson, 1981; Ensher, Craig, \& Murphy, 2001). Employees who are convinced that their organizational climate is marked by egoism and self-serving behaviors in turn may develop negative feelings about their career situation, because they believe that their employer does not meet its exchange obligations (Blau, 1964; Hsiung, Lin, \& Lin, 2012). In this scenario, employees sense that their work efforts are not fully appreciated and accordingly may express frustration or claim that insufficient opportunities exist to advance their career with the organization (Foster et al., 2011; Trembley \& Roger, 1993). That is, because they believe dysfunctional organizational politics undermine the quality of their current and future organizational functioning, stemming from their sense that rewards are based on favoritism instead of merit (Chang et al., 2012), employees may develop negative perceptions about their career and form beliefs that their career advancement is not sufficiently supported (Cao et al., 2014).

This social exchange theory-based argument also aligns with the logic of attribution theory, according to which employees may be inclined to externalize anticipated work challenges due to dysfunctional organizational politics, so that they can avoid responsibility for potential personal failures (Schroth \& Shah, 2000; Zuckerman, 1979). For example, employees might make accusations of limited organizational opportunities for career development (Chao, 1990; 
Smith-Ruig, 2009) to produce explanations for why they fail to succeed in a political climate that endorses favoritism and self-serving motives (Bradley, 1978; Mallin \& Mayo, 2006). Similarly, employees' expectations that dysfunctional organizational politics will threaten their ability to meet specific career goals (Grimland, Vigoda-Gadot, \& Baruch, 2012) may stimulate them to seek external explanations for anticipated failures, such as by attributing them to an employer's lack of investment in their career success (Foster et al., 2011). This response transfers responsibility to the employer (Bradley, 1978), so employees who suffer from highly politicized decision making are less likely to feel bad about their hampered organizational functioning in this situation (Jam et al. 2017; Siu et al., 2013).

Hypothesis 1: There is a positive relationship between employees' perceptions of organizational politics and their career plateau beliefs.

We also anticipate a negative relationship between employees' career plateau beliefs and job performance. The belief that they have reached a career plateau may diminish performanceenhancing efforts, because employees seek revenge for their adverse career situation and refuse to engage in productive activities that otherwise could contribute to their organization's wellbeing (Conner, 2014; Nachbagauer \& Riedl, 2002). Due to their desire for retaliation, which is a critical mechanism of social exchange theory (Blau, 1964; Emerson, 1981), employees thus might be less willing to devote themselves to performance-enhancing behaviors when they also believe their employer is hindering their career progress (Chao, 1990; Tremblay et al., 1995). Previous research similarly notes a connection between employees' negative perceptions of their career situation and beliefs that their employer has not met its exchange obligations (Lin et al., 2018), which leaves them reluctant to perform formal work duties (Bal, Chiaburu, \& Jansen, 2010). 
In a related vein, employees who perceive that their organization has not kept its side of the bargain or provided career development opportunities tend to feel less excited about their daily job tasks (Jawahar \& Liu, 2016), which should also spur their propensity to retaliate by allocating less time to productive activities (Blau, 1964; Quinn et al., 2012). In particular, insufficient organizational support for their career development might seem to signal that their organization does not care for their personal well-being (Wickramasinghe \& Jayaweera, 2010), which leaves them more motivated to take revenge by not performing tasks that are expected of them (Emerson, 1981). Further, employees who feel frustrated by a lack of career support may identify less strongly with their employer and be more passive in executing job tasks (Quinn et al., 2012), which likely diminishes their performance-enhancing efforts. In contrast, to the extent that they believe their employer has met its exchange obligations by providing opportunities for professional growth and supporting their career success, employees likely sense that their work contributions are valued (Blau, 1964; Chao, 1990; Smith-Ruig, 2009) and should be motivated to allocate energy to performance-enhancing activities from which their organization benefits. That is, employees who believe that their organization creates challenging opportunities that encourage their career development are more likely to fulfill the performance responsibilities specified in their job descriptions, because they want to reciprocate in a positive way and help their organization through performance-enhancing efforts (Conner, 2014; Guan, Zhou, Ye, Jiang, \& Zhou, 2015).

Hypothesis 2: Employees' career plateau beliefs relate negatively to their job performance.

Combining these arguments, we posit that employees' career plateau beliefs have a mediating role, linking perceptions of organizational politics to reduced performance outcomes. Perceptions of organizational politics relate negatively to job performance because they prompt 
employees to blame their employer for not providing more opportunities for their career development, thereby expressing their frustration about unfulfilled career-related exchange obligations (Blau, 1964; Foster et al., 2004). Previous research similarly proposes a mediating role of employees' career satisfaction in the link between the harmful effects of other adverse work situations_-such as inadequate organizational career management (Guan et al., 2015) or a lack of perceived organizational support (Cao et al., 2014)—on negative work outcomes. We extend these findings by proposing that employees' beliefs about having reached a career plateau might mediate the effect of their perceptions of organizational politics on their job performance.

Hypothesis 3: Employees' career plateau beliefs mediate the relationship between their perceptions of organizational politics and their job performance.

\section{Moderating role of leader interpersonal unfairness}

Leader interpersonal unfairness might strengthen the indirect relationship between perceptions of organizational politics and job performance, by influencing the links of both perceptions of organizational politics with career plateau beliefs and career plateau beliefs with job performance. From a social exchange perspective, leader interpersonal unfairness captures the extent to which employees believe that their immediate supervisor does not keep his or her relational obligations toward them, by being rude, not showing respect, or making inappropriate remarks or comments (Flint et al., 2013; Khalid, Bashir, Khan, \& Nida, 2018).

First, the value of career plateau beliefs as a means to express frustration about dysfunctional organizational politics should be greater to the extent that employees cannot rely on fair personal treatment by their leaders, because negative interpersonal exchange relationships exacerbate the already challenging work situation created by political organizational decision making (Kacmar \& Baron, 1999; Naseer, Raja, Syed, Donia, \& Darr, 2016). That is, when employees feel upset by rude and demeaning treatment from their supervisors, they may be 
particularly keen to express their frustrations about inadequate career support in response to the presence of dysfunctional politics (Smith-Ruig, 2009; Tremblay \& Roger, 1993). Thus, if employees do not feel protected by their supervisors, because of the lack of respect they receive in these exchange relationships, they may sense that an organizational climate based on favoritism and a behind-the-scenes mentality constitutes a particularly powerful threat to their organizational functioning (Blau, 1964; Chang et al., 2009). These negative feelings then may enhance their propensity to use their employer as a scapegoat, blaming it for devoting insufficient attention to their professional growth and career development (Bradley, 1978; Foster et al., 2004).

Hypothesis 4: The positive relationship between employees' perceptions of organizational politics and their career plateau beliefs is moderated by their exposure to leader interpersonal unfairness, such that the positive relationship is stronger at higher levels of leader interpersonal unfairness.

Second, the frustration that stems from unfair leader treatment may increase the likelihood that employees experience inadequate career support as harmful and upsetting, which increases their motivation to retaliate by spending less energy on performance-enhancing activities that enhance organizational effectiveness (Blau, 1964; Quinn et al., 2012). This invigorating effect follows the social exchange theory argument that employees tend to take revenge for unfavorable career situations by deciding where to allocate their personal energy (Chang et al., 2012; Ng, Feldman, \& Butts, 2014). That is, when the relationship with their supervisor features a lack of dignity and respect, employees may feel particularly threatened by a negative career situation that offers limited opportunities for professional growth (Lee, 2003; Wickramasinghe \& Jayaweera, 2011). Their motivation to complete their work duties thus would be undermined. Similarly, if employees cannot rely on respect-based relationships with supervisors, they may feel unprotected or vulnerable to a career situation marked by limited 
opportunities for professional advancement (Yang et al., 2009), which diminishes their dedication to performance-enhancing efforts even further (Blau, 1964). Conversely, if they regard their relationship with their supervisor as supportive, marked by high levels of respect and politeness, employees experience a positive social exchange dynamic (Flint et al., 2013) and likely believe that organizational leaders can help them improve their current career situation (Colquitt \& Rodell, 2011). Their propensity to retaliate for experienced career plateaus, in the form of halted performance-enhancing activities, then might be thwarted.

Hypothesis 5: The negative relationship between employees' career plateau beliefs and their job performance is moderated by their exposure to leader interpersonal unfairness, such that the negative relationship is stronger at higher levels of leader interpersonal unfairness.

These arguments also imply a potential moderated mediation effect (Preacher, Rucker, \& Hayes, 2007). Leader interpersonal unfairness may serve as a contingent factor that invigorates the indirect effect of employees' perceptions of organizational politics on their job performance, through their career plateau beliefs. At high levels of leader interpersonal unfairness, which functions as a catalyst, beliefs about a stalled career path get more easily triggered as causal mechanisms that convert dysfunctional politics into reduced job performance (Foster et al., 2011; Smith-Ruig, 2009). That is, their exposure to unsupportive supervisor relationships, marked by low levels of respect and dignity, exacerbates the likelihood that employees feel frustrated about the presence of self-serving political climates (Miller, Rutherford, \& Kolodinsky, 2008). This situation in turn enhances their propensity to blame the organization, which has not met its exchange obligations, for the perceived career plateau (Blau et al., 1964; Chang et al., 2012), which then also reduces their propensity to undertake performance-enhancing activities. In short, to the extent that employees who suffer from dysfunctional politics also are unfairly treated by 
organizational leaders, their failure to fulfill their job duties can be explained more fully by their beliefs about the presence of inadequate career support.

Hypothesis 6: The indirect relationship between employees' perceptions of organizational politics and their job performance, through their career plateau beliefs, is moderated by their exposure to leader interpersonal unfairness, such that this indirect relationship is stronger at higher levels of leader interpersonal unfairness.

\section{Method}

\section{Sample and data collection}

To test our research hypotheses, we collected data from members of 16 Pakistani organizations that operate in a variety of industry sectors, including telecom, textiles, banking, pharmaceuticals, and education. By including multiple organizations and sectors, we sought to enhance the external validity of the findings, as well as capture sufficient variance in the study's focal constructs, particularly employees' career plateau beliefs. One of the researchers leveraged existing professional contacts to identify target organizations with at least 100 employees, to ensure career development issues and career plateau beliefs would be relevant; after receiving organizational endorsement, this researcher made personal visits to the company sites to distribute the surveys randomly to potential participants.

The data collection used a three-wave design, with a time lag of two weeks between each round. These lags may not completely exclude the possibility of reverse causality-in that career plateau beliefs arguably could spur perceptions about adverse political decision-making processes, or low job performance might spur frustrations about stalled careers - but they reduce the possibility substantially better than a cross-sectional design could. The first two surveys gathered employees' responses, regarding their perceptions of organizational politics and their

relationships with their supervisor and then their career plateau beliefs; the third survey, distributed to supervisors, asked the supervisors to assess their employees' job performance. The 
surveys were administered in English, the official language of communication in higher education and business in Pakistan. After answering the survey questions, participants put their completed surveys in sealed envelopes and returned them to the research team.

To limit social desirability biases, we took several measures. In particular, the letters that accompanied the surveys highlighted the general purpose of the research, emphasized complete confidentiality, clarified that participation was completely voluntary, and promised participants that their organizations would not know who participated. Furthermore, we explicated that only summary data would be included in any academic output. We also noted that participants should answer the questions as honestly as possible, that there were no correct or incorrect answers, and that it was normal for employees to vary in their responses. These features all can reduce social desirability biases that might arise when gathering sensitive information about employees' perceptions of their work environment (Spector, 2006). The letters also provided contact information for one member of the research team, so participants could ask questions or provide feedback if they wished. Finally, respondents learned that they could withdraw from the study at any point. Thus, though we cannot completely rule out the possibility of social desirability biases, these standard data collection procedures significantly reduce this concern.

Of the 450 surveys distributed in the first round, we received 298 completed responses. Two weeks later, we contacted these respondents again, using the same onsite data collection procedure, which generated 262 completed responses. Finally, the supervisors of 230 secondround respondents rated their employees' job performance. Thus, the study's analyses are based on 230 completed response sets, for an overall response rate of $51 \%$.

\section{Measures}


Perceptions of organizational politics. To assess employees' perceptions of the presence of dysfunctional self-serving behaviors, we relied on Kacmar and Ferris's (1991) 12-item scale of perceived organizational politics, using 5-point Likert anchors. Sample items included "Favoritism not merit gets people ahead," "One group always gets their way," "People build themselves up by tearing others down," and "There is an influential group no one crosses" (Cronbach's alpha $=.82)$.

Leader interpersonal unfairness. We assessed the extent to which employees were the victims of disrespectful treatment by their supervisor with a four-item scale of interpersonal fairness, using 5-point Likert anchors (Colquitt, 2001). Similar to prior research on leader interpersonal unfairness (Yang et al., 2013), and to be consistent with our conceptual framework, we reverse coded the responses before calculating the composite score. Sample items included "My supervisor treats me with respect" and "My supervisor refrains from improper remarks or comments" (Cronbach's alpha $=.92)$.

Career plateau beliefs. To measure employees' sense that their organization does not provide adequate opportunities for their career development, we applied a six-item, 7-point Likert scale of career plateaus, drawn from previous studies (Foster et al., 2004, 2011). The respondents indicated, for example, whether "In this organization, the opportunities for my career development are limited," "I don't foresee any opportunities to grow in this company," and "The nature of the work assigned to me is repetitive and routine" (Cronbach's alpha $=.73$ ).

Job performance. We measured supervisor-rated job performance with a seven-item scale developed by Williams and Anderson (1991), using 5-point Likert anchors. Sample items included, "This employee performs the tasks that are expected of him or her," "This employee 
neglects aspects of the job that he or she is obligated to perform" (reverse coded), and "This employee fulfills the responsibilities specified in his or her job" $($ Cronbach's alpha $=.93){ }^{1}$

Control variables. The statistical models controlled for three variables: gender $(1=$ female), age ( $1=$ below 20 years, $2=21-40$ years, $3=41-60$ years, $4=$ above 60 years $)$, and organizational tenure $(1=$ below 5 years, $2=6-10$ years, $3=11-15$ years, $4=15-20$ years, $5=$ above 20 years). These variables are potentially relevant to employees' career plateau beliefs: Gender discrimination might make it more likely that female employees have a sense that there are no opportunities for career progress in their organization (Miller \& Wheeler, 1992; Smith, Caputi, \& Crittenden, 2012), older employees might experience more restrictions on their upward career mobility (Kalleberg \& Loscocco, 1983; Pond \& Geyer, 1987), and employees who have worked for the organization for longer might have higher expectations of how their employer should treat them (Lim \& Teo, 1998; Mills, 1985).

\section{Results}

Table 1 reports the correlations and descriptive statistics of the study variables, and Table 2 contains the hierarchical regression results. Models 1-3 predict career plateau beliefs, and Models 4-6 predict job performance. In each model, the variance inflation factor is lower than the conservative cut-off value of 5.0, so multicollinearity is not a concern. ${ }^{2}$

[Insert Tables 1 and 2 about here]

\footnotetext{
${ }^{1}$ A confirmatory factor analysis to test for the convergent validity of each focal construct generated strongly significant factor loadings for each item on its constructs $(p<.001)$. In support of discriminant validity, for each pair of focal constructs, the fit of a constrained model in which their correlation was set to equal 1 was significantly worse $\left(\Delta \chi^{2}(1)>10.83, p<.001\right)$ than that of a corresponding, unconstrained model. For example, the $\Delta \chi^{2}(1)$ value for the perceived organizational politics-leader interpersonal fairness pair, which had the highest interconstruct correlation, was 540.44 .

${ }^{2}$ In light of our reliance on both employee and supervisor data, we assessed the two pertinent interclass coefficients, ICC(1) and ICC(2), to check whether it was appropriate to apply hierarchical linear modeling to test the hypotheses. It was not. The ICC(1) values for the four focal constructs are all smaller than .10, indicating only small group effect sizes (Bliese, 2000; Murphy \& Myors, 1998). The ICC(2) values, all smaller than .50, further indicate low reliabilities for the group means of the focal constructs (Nunnally \& Bernstein, 1994).
} 
Hypothesis 1 predicted that employees who believe that dysfunctional political behaviors are prevalent in their work environments may develop a sense that their employer does not provide adequate career support. In support of this prediction, Model 2 reveals a positive relationship between perceptions of organizational politics and career plateau beliefs ( $\beta=.171, p$ $<.05)$. The results also offer support for our prediction that negative beliefs about the absence of career support reduce the likelihood that employees undertake performance-enhancing activities, as shown in the negative relationship between career plateau beliefs and job performance in Model $5(\beta=-.238, p<.05)$.

To assess the presence of a mediation by career plateau beliefs, we applied the bootstrapping method suggested by Preacher and Hayes (2004), using the Process macro developed by Hayes (2013). This approach generates confidence intervals (CIs) for the indirect effect of perceptions of organizational politics on job performance, thereby avoiding the statistical power problems that might be caused by asymmetric and other non-normal sampling distributions (MacKinnon, Lockwood, \& Williams, 2004). Using 10,000 random samples and replacement from the full sample, we find that the CI for the indirect effect of perceptions on organizational politics on job performance through career plateau beliefs does not include 0 [$.114 ;-.004]$, indicating the presence of mediation.

To test the individual moderating effects of leader interpersonal unfairness, as postulated in Hypotheses 4 and 5, we calculated two interaction terms: perceptions of organizational politics $\times$ leader interpersonal unfairness to predict career plateau beliefs (Model 3) and career plateau beliefs $\times$ leader interpersonal unfairness to predict job performance (Model 6). Both interaction terms are significant $(\beta=.184, p<.01 ; \beta=-.295, p<.05$, respectively). To visualize these findings, we plot the effect of perceptions of organizational politics on career plateau beliefs in 
Figure 2 and the effect of career plateau beliefs on job performance in Figure 3, at high and low levels of leader interpersonal unfairness, together with a simple slope analysis for each. The simple slope analysis in Figure 2 reveals that the relationship between perceptions of organizational politics and career plateau beliefs is strong and significant at high levels of leader interpersonal unfairness $(\beta=.308, p<.001)$ but not significant at low levels $(\beta=-.060, n s)$, in support of Hypothesis 4. Similarly, the simple slope analysis in Figure 3 indicates that the negative relationship between career plateau beliefs and job performance is strong and significant at high levels of leader interpersonal unfairness $(\beta=-.600, p<.001)$ but not at low levels $(\beta=-.010, n s)$, in support of Hypothesis 5. That is, leader interpersonal unfairness has invigorating effects on both relationships.

[Insert Figures 2 and 3]

To test for the moderated mediation effect advanced in Hypothesis 6, we relied on Preacher et al.’s (2007) procedure and Hayes's (2013) Process macro. Similar to the bootstrapping method to assess mediation, the procedure in this scenario provides CIs rather than point estimates for the conditional indirect effects (MacKinnon et al., 2004). As specified in Hayes's (2013) Process macro, the CIs pertain to different levels of the moderator (i.e., $10^{\text {th }}, 25^{\text {th }}$, $50^{\text {th }}, 75^{\text {th }}$, and $90^{\text {th }}$ percentiles). In line with our conceptual framework, the estimated model includes moderating effects of leader interpersonal unfairness on the relationship between perceptions of organizational politics and career plateau beliefs and between career plateau beliefs and job performance. The bootstrap 95\% CIs for the conditional indirect effect of perceptions of organizational politics on job performance at the $10^{\text {th }}, 25^{\text {th }}$, and $50^{\text {th }}$ percentiles of leader interpersonal unfairness contain 0 ([-.090; .076], [-.031; .054], and [-.064; .033], respectively), but they do not contain 0 at the $75^{\text {th }}$ and $90^{\text {th }}$ percentiles $([-.394 ;-.085]$ and $[-.622$; 
-.120], respectively). Thus, leader interpersonal unfairness invigorates the negative indirect effect of perceptions of organizational politics on job performance, through career plateau beliefs, in support of Hypothesis 6 and our overall theoretical framework.

\section{Discussion}

With this study we have sought to extend extant research by unpacking the relationship between employees' perceptions of organizational politics and their job performance, as well as by considering unexplored factors that inform this process. Despite some previous insights into how exposure to dysfunctional organizational politics might undermine employee success (e.g., Abbas et al., 2014; Crawford, LePine, \& Rich, 2010), more studies are needed to detail how and when this process unfolds (Yang, 2017). To fill this gap, we have drawn from social exchange theory (Blau, 1964; Emerson, 1981), as well as attribution theory (Zuckerman, 1979), to argue that (1) the likelihood of reduced job performance in the presence of organizational politics might arise because employees believe that their organization does not support their career development and (2) their exposure to disrespectful leader treatment invigorates this process. The empirical results confirm these theoretical predictions.

In particular, we highlight an important reason that perceptions of dysfunctional politics — which are predicated on self-serving motives and favoritism (Abbas et al., 2014) and generate a disconnect between employees' work efforts and organizational rewards (Chang et al., 2012) - might thwart job performance: Employees develop beliefs about a stalled career (Chao, 1990; Foster et al., 2011). Specifically, the belief that their employer does not offer sufficient opportunities for professional growth and development serves as a mechanism by which a dysfunctional political climate transforms into reduced job performance. Previous studies have used social exchange theory to establish that employees who operate in highly politicized work 
environments experience a violation of their exchange relationship with their employer, and the accompanying frustration negatively affects their current and future organizational functioning (Chang et al., 2012; Hsiung et al., 2012; Yang, Pandey, Liao, \& Dobson, 2017). Prior research that draws from attribution theory also suggests that accusations of inadequate organizational support can be used to blame negative expected work outcomes on external causes (De Clercq et al., 2018; Schroth \& Shah, 2000). We combined these two theories and added to this research stream by explicating that blaming their employer for providing insufficient career support may help employees who operate in highly politicized work environments express their frustration about unmet exchange obligations by their employer. In turn, and consistent with the social exchange logic, beliefs about a stalled career increase the chances that employees refrain from productive, performance-enhancing activities, because they seek to take revenge for this negative career situation (Blau, 1964; Guan et al., 2015).

The mediating role of career plateau beliefs also is moderated by employees' exposure to leader interpersonal unfairness, which captures the extent to which employees are victims of rude treatment from their organizational leaders (Colquitt et al., 2001; Yang et al., 2013). Career plateau beliefs connect perceptions of organizational politics to reduced job performance more powerfully when employees also worry that their organizational functioning is threatened by supervisors with whom they have poor exchange relationships, as manifest in a lack of respect or concern for employees' well-being (Flint et al., 2013). In highlighting this moderated mediation mechanism, we add to previous studies that focus on how adverse leader relationships moderate the direct negative link between dysfunctional political games and positive work outcomes (e.g., Bouckenooghe, 2012; Rosen et al., 2011). In our study, the likelihood that employees express frustration with dysfunctional political games, by pointing to the absence of adequate career 
support (Foster et al., 2011) and then avoiding performance-enhancing activities (Conner, 2014), gets activated by the presence of unfair interpersonal relationships with supervisors. We thus establish a reinforcing dynamic between employees' negative perceptions of their social exchange relationships with two key entities: the employing organization and the immediate supervisor (Flint et al., 2013; Masterson et al., 2000). When employees are victims of rude supervisor treatment, their unhappiness with how organizational leaders interact with them triggers those already suffering from dysfunctional politics to retaliate, by using claims about inadequate organizational career management as reasons to reduce the personal energy they allocate to performance-enhancing activities (Blau, 1964).

Overall, this study thus offers deeper understanding of the negative performance consequences of highly politicized organizational environments. In particular, it pinpoints how negative feelings about organizational career support (i.e., having reached a career plateau) provide explanatory links from perceived organizational politics to reduced job performance. It also reveals how exposure to disrespectful treatment by organizational leaders invigorates this process. As we mentioned at the outset, Pakistan's cultural context—namely, its high collectivism and power distance, which might make political decision-making processes and unfair leader treatment relatively common and hence more acceptable, but also its high risk aversion, which implies that uncertainty-invoking work features represent stressful violations of social exchange obligations (Naseer et al., 2016) — makes this country highly relevant for testing our theoretical framework (Hofstede et al., 2010). The general support for our hypotheses indicates that the latter logic supersedes the former: The combination of dysfunctional organizational politics and disrespectful leader treatment offer pertinent explanations for 
employees' negative beliefs about their career situation, as well as their subsequent reluctance to enhance organizational well-being through performance efforts.

\section{Limitations and further research}

This study has some limitations, which suggest avenues for research. First, we focused on career plateau beliefs as explanatory mechanisms that can clarify how organizational politics might hinder job performance, informed by calls for more studies of how career dissatisfaction might lead to negative work outcomes in adverse organizational climates (Conner, 2014; Guan et al., 2015; Jawahar \& Liu, 2016). It would be interesting to investigate other unexplored mediators too, such as employees' psychological withdrawal (Schilpzand, Leavitt, \& Lim, 2016) or perceptions of psychological contract breaches (Raja, Johns, \& Ntalianis, 2004). In a related vein, we did not directly capture the mechanism that we theorized would link highly politicized decision making to career plateau beliefs, namely, employees' desire to express frustration about unmet career-related obligations by their organization. This mechanism is anchored in social exchange and attribution theories; employees who feel upset about unmet organizational obligations likely seek to blame the organization for what they regard as salient explanations for their failure to succeed in an organization that embraces favoritism and egoism (Blau, 1964; Zuckerman, 1979). Additional research could measure this mechanism directly.

Second, our consideration of leader interpersonal unfairness as a contingency factor that invigorates the indirect relationship of perceptions of organizational politics with job performance might be complemented by other catalyzing contextual factors, such as incompatible goals between employees and organizational leaders (Bouckenooghe, Zafar, \& Raja, 2015) or ambiguous job role descriptions (Eatough, Chang, Miloslavic, \& Johnson, 2011). Certain personal factors also might influence the likelihood that employees who suffer from 
dysfunctional organizational politics blame their anticipated personal failures on inadequate career support, such as their neuroticism (De Hoogh \& Den Hartog, 2009) or risk sensitivity (Vandenberghe, Panaccio, \& Ayed, 2011).

Third, Pakistan is highly relevant for testing the conceptual framework, and the arguments underpinning our research hypotheses were not country-specific, so we expect that the strength, rather than the nature, of the hypothesized relationships might vary across different country settings. Still, it would be interesting to perform cross-country comparisons of whether and how negative career-related beliefs explain the harmful performance consequences of dysfunctional political behaviors, as well as the roles of different moderators in this process, in country contexts that differ from Pakistan's.

\section{Practical implications}

For organizations, this study shows that exposing employees to dysfunctional political behaviors, marked by self-serving motives or behind-the-scenes decision making, invokes negative feelings about their career situation, with detrimental consequences for their propensity to allocate personal energy to performance-enhancing activities. Accordingly, organizations should attempt to discourage such political behaviors. Some employees might be reluctant, though, to admit that they suffer from politicized decision-making processes, for fear that they could be perceived as weak or overly complaining (Kacmar \& Baron, 1999; Miller et al., 2008). Organizations accordingly should make every effort to identify the presence and persistence of dysfunctional politics and eliminate their possible origins, such as inadequate recruitment or promotion policies or excessive internal rivalry for company resources.

In addition to this general recommendation, this study offers unique insights for organizations that cannot completely eradicate dysfunctional politics. Employees who suffer 
from an organizational climate marked by self-serving motives and favoritism may believe that their employer is not meeting its exchange obligations toward them, so to vent their frustrations, they may blame the organization for failing to provide sufficient support for their career advancement, which then turns them away from productive, performance-enhancing activities. This challenge is particularly salient when employees also are exposed to organizational leaders who treat them with disrespect (Yang et al., 2013). Therefore, to avoid the negative performance consequences of dysfunctional politics, due to the development of negative career beliefs, organizations should try to match unavoidably adverse work environments with an appropriate relational context, in which employees sense that their leaders appreciate their work contributions and treat them with dignity and respect. Leader relationships marked by interpersonal fairness can help alleviate the frustration that employees who suffer from highly politicized decision making experience during the execution of their job tasks. When employees can count on the support and respect of their leaders, they may become less sensitive to the hardships associated with self-serving decision making (Chang et al., 2012; Johnson et al., 2017), which should mitigate their beliefs that the organization does not care about their career development. Ultimately, the tendency to halt or limit their performance-enhancing activities thus might be contained more easily. 


\section{References}

Abbas, M., Raja, U., Darr, W., \& Bouckenooghe, D. (2014). Combined effects of perceived politics and psychological capital on job satisfaction, turnover intentions, and performance. Journal of Management, 40, 1813-1830.

Appelbaum, S.H. (1994). Revisiting career plateauing. Journal of Management Psychology, 9, $12-21$.

Bal, P.M., Chiaburu, D.S., \& Jansen, P.G.W (2010). Psychological contract breach and work performance: Is social exchange a buffer or an intensifier? Journal of Managerial Psychology, 25, 252-273.

Blau, P. (1964). Exchange and power in social life. New York: Wiley.

Bliese, P.D. (2000). Within-group agreement, non-independence, and reliability: Implications for data aggregation and analysis. In K.J. Klein \& S.W.J. Kozlowski (Eds.), Multilevel theory, research, and methods in organizations (pp. 349-381). San Francisco: Jossey-Bass.

Bouckenooghe, D. (2012). The role of organizational politics, contextual resources, and formal communication on change recipients' commitment to change: A multilevel study. European Journal of Work and Organizational Psychology, 21, 575-602.

Bouckenooghe, D., Zafar, A., \& Raja, U. (2015). How ethical leadership shapes employees' job performance: The mediating roles of goal congruence and psychological capital. Journal of Business Ethics, 129, 251-264.

Bradley, G.W. (1978). Self-serving biases in the attribution process: A reexamination of the fact or fiction questions. Journal of Personality and Social Psychology, 36, 56-71.

Brouer, R.L., Harris, K., \& Kacmar, K.M. (2011). The moderating effects of political skill on the perceived politics-outcome relationships. Journal of Organizational Behavior, 32, 869-885.

Cao, L., Hirschi, A., \& Deller, J. (2014). Perceived organizational support and intention to stay in host countries among self-initiated expatriates: the role of career satisfaction and networks. International Journal of Human Resource Management, 25, 2013-2032.

Chang, C.-H., Rosen, C. C., \& Levy, P. E. (2009). The relationship between perceptions of organizational politics and employee attitudes, strain, and behavior: a meta-analytic examination. Academy of Management Journal, 52, 779-801.

Chang, C.-H., Rosen, C.C., Siemieniec, G.M., \& Johnson, R.E. (2012). Perceptions of organizational politics and employee citizenship behaviors: Conscientiousness and selfmonitoring as moderators. Journal of Business and Psychology, 27, 395-406.

Chao, G.T. (1990). Exploration of the conceptualization and measurement of career plateau: A comparative analysis. Journal of Management, 16, 181-193.

Colquitt, J. (2001). On the dimensionality of organizational justice: A construct validation of a measure. Journal of Applied Psychology, 86, 386-400.

Colquitt, J. A., Conlon, D. E., Wesson, M. J., Porter, C. O. L. H., \& Ng, K. Y. (2001). Justice at the millennium: A meta-analytic review of 25 years of organizational justice research. Journal of Applied Psychology, 86, 425-445.

Colquitt, J.A., \& Rodell, J.B. (2011). Justice, trust, and trustworthiness: A longitudinal analysis integrating three theoretical perspectives. Academy of Management Journal, 54, 1183-1206.

Conner, D. (2014). The effects of career plateaued workers on in-group members' perceptions of P-O fit. Employee Relations, 36, 198-212. 
Crawford, E. R., LePine, J. A., \& Rich, B. L. (2010). Linking job demands and resources to employee engagement and burnout: A theoretical extension and meta-analytic test. Journal of Applied Psychology, 93, 834-848.

Cropanzano, R., Prehar, C., \& Chen, P. (2002). Using social exchange theory to distinguish procedural from interactional justice. Group \& Organization Management, 27, 324-351.

De Clercq, D., \& Belausteguigoitia, I. (2017). Mitigating the negative effect of perceived organizational politics on organizational citizenship behavior: Moderating roles of contextual and personal resources. Journal of Management and Organization, 23, 689-708.

De Clercq, D., Haq, I.U., \& Azeem, M.U. (2018). Role ambiguity and perceptions of unfair performance appraisals: Mitigating roles of personal resources. Asia Pacific Journal of Human Resources, doi: 10.1111/1744-7941.12178.

De Hoogh, A.H.B., \& Den Hartog, D. N. (2009). Neuroticism and locus of control as moderators of the relationships of charismatic and autocratic leadership with burnout. Journal of Applied Psychology, 94, 1058-1067.

Eatough, E.M., Chang, C.H., Miloslavic, S.A., \& Johnson, R.E. (2011). Relationships of role stressors with organizational citizenship behavior: A meta-analysis. Journal of Applied Psychology, 96, 619-632.

Emerson, R. M. (1981). Social exchange theory. In M. Rosenberg \& R.H. Turner (Eds.), Social psychology: Sociological perspectives. New York: Basic Books, Inc.

Ensher, E.A., Craig, T., \& Murphy, S.E. (2001). Comparison of traditional, step-ahead, and peer mentoring on protégés' support, satisfaction, and perceptions of career success: A social exchange perspective. Journal of Business and Psychology, 15, 419-438.

Flint, D., Haley, L.M., \& McNally, J.J. (2013). Individual and organizational determinants of turnover intent. Personnel Review, 42, 552-572.

Foster, B.P., Lonial, S., \& Shastri, T. (2011). Mentoring, career plateau tendencies, turnover intentions and implications for narrowing pay and position gaps due to gender: Structural equations modeling. Journal of Applied Business Research, 27, 71-84.

Foster, B.P., Shastri, T., \& Withane, S. (2004). The impact of mentoring on career plateau and turnover intentions of management accountants. Journal of Applied Business Research, 20, 33-43.

Grimland, S., Vigoda-Gadot, E., \& Baruch, Y. (2012). Career attitudes and success of managers: The impact of chance event, protean, and traditional careers. The International Journal of Human Resource Management, 23, 1074-1094.

Guan, Y., Zhou, W., Ye, L., Jiang, P., \& Zhou, Y. (2015). Perceived organizational career management and career adaptability as predictors of success and turnover intention among Chinese employees. Journal of Vocational Behavior, 88, 230-237.

Hayes, A.F. (2013). Introduction to mediation, moderation, and conditional process analysis: A regression-based approach. New York: Guilford Press.

Hofstede, G.H., Hofstede, G.J., \& Minkov, M. (2010). Cultures and organizations: Software of the mind. Intercultural cooperation and its importance for survival ( $3^{\text {rd }} \mathrm{ed}$.). New York: McGraw-Hill.

Hsiung, H.-H., Lin, C.-W., \& Lin, C.-S. (2012). Nourishing or suppressing? The contradictory influences of perception of organizational politics on organizational citizenship behaviour. Journal of Occupational and Organizational Psychology, 85, 258-276. 
Jam, F.A., Donia, M.B.L., Raja, U., \& Ling, C.H. (2017). A time-lagged study on the moderating role of overall satisfaction in perceived politics: Job outcomes relationships. Journal of Management and Organization, 23, 321-336.

Jawahar, I.M., \& Liu, Y. (2016). Proactive personality and citizenship performance: The mediating role of career satisfaction and the moderating role of political skill. Career Development International, 21, 378-401.

Johnson, L.U., Rogers, A., Stewart, R., David, E.M., \& Witt, L.A. (2017). Effects of politics, emotional stability, and LMX on job dedication. Journal of Leadership \& Organizational Studies, 24, 121-130.

Judge, T.A., \& J. A. Colquitt, J.A. (2004). Organizational justice and stress: the mediating role of work-family conflict, Journal of Applied Psychology, 89, 395-404.

Kacmar, K.M., \& Baron, R.A. (1999). Organizational politics: The state of the field, links to related processes, and an agenda for future research. In G. Ferris (Ed.), Research in personnel and human resource management. Greenwich, CT: JAI Press.

Kacmar, K.M., \& Ferris, G.R. (1991). Perceptions of organizational politics scale (POPS): Development and construct validation. Educational and Psychological Measurement, 51, 193-205.

Kalleberg, A.L., \& Loscocco, K.A. (1983). Aging, values, and rewards: Explaining age differences in job satisfaction. American Sociology Review, 48, 78-80.

Khalid, M., Bashir S., Khan, A.K., \& Nida, A. (2018). When and how abusive supervision leads to knowledge hiding behaviors. Leadership \& Organization Development Journal, 39, 794806.

Khan, A.K., Moss, S., Quratulain, S., \& Hameed, I. (2016). When and how subordinate performance leads to abusive supervision: A social dominance perspective. Journal of Management, doi: 10.1177/0149206316653930

Khan, A.K., Quratulain, S. \& Crawshaw, J. (2017). Double jeopardy: Subordinates' worldviews and poor performance as predictors of abusive supervision. Journal of Business and Psychology, 32, 165-178.

Kulkarni, S., \& Ramamoorthy, N. (2017). The psychological foundations of supervisorsubordinate information asymmetry. Organization Studies, 38, 1445-1466.

Lee, P.C.B. (2003). Going beyond career plateau: Using professional plateau to account for work outcomes. Journal of Management Development, 22, 538-551.

Lemire, L., Saba, T., \& Gagnon, Y. (1999). Managing career plateauing in the Quebec public sector. Public Personnel Management, 28, 375-391.

Li, Y., Xu, J., Tu, Y., \& Lu, X. (2014). Ethical leadership and subordinates' occupational wellbeing: A multi-level examination in China. Social Indicators Research, 116, 823-842.

Lim, V.K.G., \& Teo, T.S.H. (1998). Effects of individual characteristics on police officers' work-related attitudes. Journal of Managerial Psychology, 13, 334-342.

Lin, Y.-C., Chen, A.S.-Y., \& Lai, Y.-T. (2018). Breach or bridge your career? Understanding the relationship between career plateau and internal employability. Personnel Review, 47, 9861002.

MacKinnon, D.P., Lockwood, C.M., and Williams, J. (2004). Confidence limits for the indirect effect: Distribution of the product and resampling methods. Multivariate Behavioral Research, 39, 99-128. 
Masterson, S.S., Lewis, K., Goldman, B.M., \& Taylor, M.S. (2000). Integrating justice and social exchange. The differing effects of fair procedures and treatment on work relationships. Academy of Management Journal, 43 (4), 738-748.

Miller, B.K., Rutherford, M.A., \& Kolodinsky, R.W. (2008). Perceptions of organizational politics: A meta-analysis of outcomes. Journal of Business and Psychology, 22, 209-222.

Miller, J.G., \& Wheeler, K.G. (1992). Unraveling the mysteries of gender differences in intentions to leave the organization. Journal of Organizational Behavior, 13, 465-478.

Mills, Q.D. (1985). Seniority vs. ability in promotion decisions. Industrial and Labor Relations Review, 38, 421-425.

Murphy, K.R., \& Myors, B. (1998). Statistical power analysis: A simple and general model for traditional and modern hypothesis tests. Mahwah, NJ: Lawrence Erlbaum.

Nachbagauer, A.G M., \& Riedl, G. (2002). Effects of concepts of career plateaus on performance, work satisfaction and commitment. International Journal of Manpower, 23, 716-733.

Naseer, S., Raja, U., Syed, F., Donia, M.B.L., \& Darr, W. (2016). Perils of being close to a bad leader in a bad environment: Exploring the combined effects of despotic leadership, leader member exchange, and perceived organizational politics on behaviors. Leadership Quarterly, 27, 14-33.

Ng, T.W.H., Feldman, D.C., \& Butts, M.M. (2014). Psychological contract breaches and employee voice behaviour: The moderating effects of changes in social relationships. European Journal of Work and Organizational Psychology, 23, 537-553.

Nunnally, J.C., \& Bernstein, I.H. (1994). Psychometric theory (3d ed.). New York: McGrawHill.

Parker, C.P., Dipboye, R.L., \& Jackson, S.L. 1995. Perceptions of organizational politics: An investigation of antecedents and consequences. Journal of Management, 21, 891-912.

Pond, S.B., \& Geyer, P. (1987). Employee age as a moderator of the relation between perceived work alternatives and job satisfaction. Journal of Applied Psychology, 72, 552-557.

Poon, J.M.L. (2003). Situational antecedents and outcomes of organizational politics perceptions. Journal of Managerial Psychology, 18, 138-155.

Preacher, K.J., \& Hayes, A.F. (2004). SPSS and SAS procedures for estimating indirect effects in simple mediation models. Behavior Research Methods, Instruments, \& Computers, 36, 717-731.

Preacher, K.J., Rucker, D.D., \& Hayes, A.F. (2007). Assessing moderated mediation hypotheses: Theory, methods, and prescriptions, Multivariate Behavioral Research, 42, 185-227.

Quinn, R.W., Spreitzer, G.M., \& Lam, C.F. (2012). Building a sustainable model of human energy in organizations: Exploring the critical role of resources. Academy of Management Annals, 6, 337-396.

Raja, U., Johns, G., \& Ntalianis, F. (2004). The impact of personality on psychological contracts. Academy of Management Journal, 47, 350-367.

Rosen, C.C., Harris, K.J., \& Kacmar, K.M. (2011). LMX, context perceptions, and performance: An uncertainty management perspective. Journal of Management, 37, 819-838.

Rotondo, D.M., \& Perrewé, P.L. (2000). Coping with a career plateau: An empirical examination of what works and what doesn't. Journal of Applied Social Psychology, 30, 2622-2646.

Rusbult, C., Campbell, M., \& Price, M. (1990). Rational selective exploitation and distress: Employee reactions to performance-based and mobility-based reward allocations. Journal of Personality and Social Psychology, 59, 487-500. 
Schilpzand, P., Leavitt, K., \& Lim, S. (2016). Incivility hates company: Shared incivility attenuates rumination, stress, and psychological withdrawal by reducing self-blame. Organizational Behavior and Human Decision Processes, 133, 33-44.

Schroth, H.A., \& Shah, P.P. (2000). Procedures: Do we really want to know them? An examination of the effects of procedural justice on self-esteem. Journal of Applied Psychology, 85, 462-471.

Siu, O.-L., Lu, C.-Q., \& Spector, P.E. (2013). Direct and indirect relationship between social stressors and job performance in Greater China: The role of strain and social support. European Journal of Work and Organizational Psychology, 22, 520-531.

Smith, P., Caputi, P., \& Crittenden, N. (2012). How are women's glass ceiling beliefs related to career success? Career Development International,17, 458-474.

Smith-Ruig, T. (2009). Exploring career plateau as a multi-faceted phenomenon: Understanding the types of career plateaus experienced by accounting professionals. British Journal of Management, 20, 610-622.

Spector, P.E. (2006). Method variance in organizational research: Truth or urban legend? Organizational Research Methods, 9, 221-232.

Tremblay, M., \& Roger, A. (1993). Individual, familial, and organizational determinants of career plateau: An empirical study of the determinants of objective and subjective career plateau in a population of Canadian managers. Group \& Organization Studies, 18, 411-435.

Tremblay, M., Roger, A., \& Toulouse, J.-M. (1995). Career plateau and work attitudes: An empirical study of managers. Human Relations, 48, 221-237.

Vandenberghe, C., Panaccio, A., \& Ayed, A.K.B. (2011). Continuance commitment and turnover: Examining the moderating role of negative affectivity and risk aversion. Journal of Occupational and Organizational Psychology, 84, 403-424.

Wickramasinghe, V., \& Jayaweera, M. (2010). Impact of career plateau and supervisory support on career satisfaction: A study in offshore outsourced IT firms in Sri Lanka. Career Development International, 15, 544-561.

Wickramasinghe, V., \& Jayaweera, M. (2011). Career management strategies among IT professionals in offshore outsourced IT firms in Sri Lanka. Journal of Management Development, 30, 914-926.

Williams, L.J., \& Anderson, S.E. (1991). Job satisfaction and organizational commitment as predictors of organizational citizenship and in-role behaviors. Journal of Management, 17, 601-617.

Yang, F. (2017). Better understanding the perceptions of organizational politics: its impact under different types of work unit structure. European Journal of Work and Organizational Psychology, 26, 250-262.

Yang, L.-Q., Johnson, R.E., Zhang, X., Spector, P.E., \& Xu, S. (2013). Relations of interpersonal unfairness with counterproductive work behavior: The moderating role of employee selfidentity. Journal of Business and Psychology, 28, 189-202.

Yang, T.S., Pandey, A., Liao, Y.-C., \& Dobson, J.J. (2017). A path from job autonomy to organizational citizenship behavior: The role of perceived organizational politics as mediator. Journal of Business and Behavioral Sciences, 29, 44-56.

Yang, W.-N., Johnson, S., \& Niven, K. (2018). “That's not what I signed up for!” A longitudinal investigation of the impact of unmet expectation and age in the relation between career plateau and job attitudes. Journal of Vocational Behavior, 107, 71-85. 
Yang, J., Mossholder, K.W., \& Peng, T.K. (2009). Supervisory procedural justice effects: the mediating roles of cognitive and affective trust. Leadership Quarterly, 20, 143-154.

Yen, W.-W. (2015). Relationships among perceptions of organizational politics (POPs), work motivation and salesperson performance. Journal of Management \& Organization, 21, $203-$ 216.

Zuckerman, M. (1979). Attribution of success and failure revisited: or The motivational bias is alive and well in attribution theory. Journal of Personality, 47, 245-287. 
Figure 1. Conceptual model

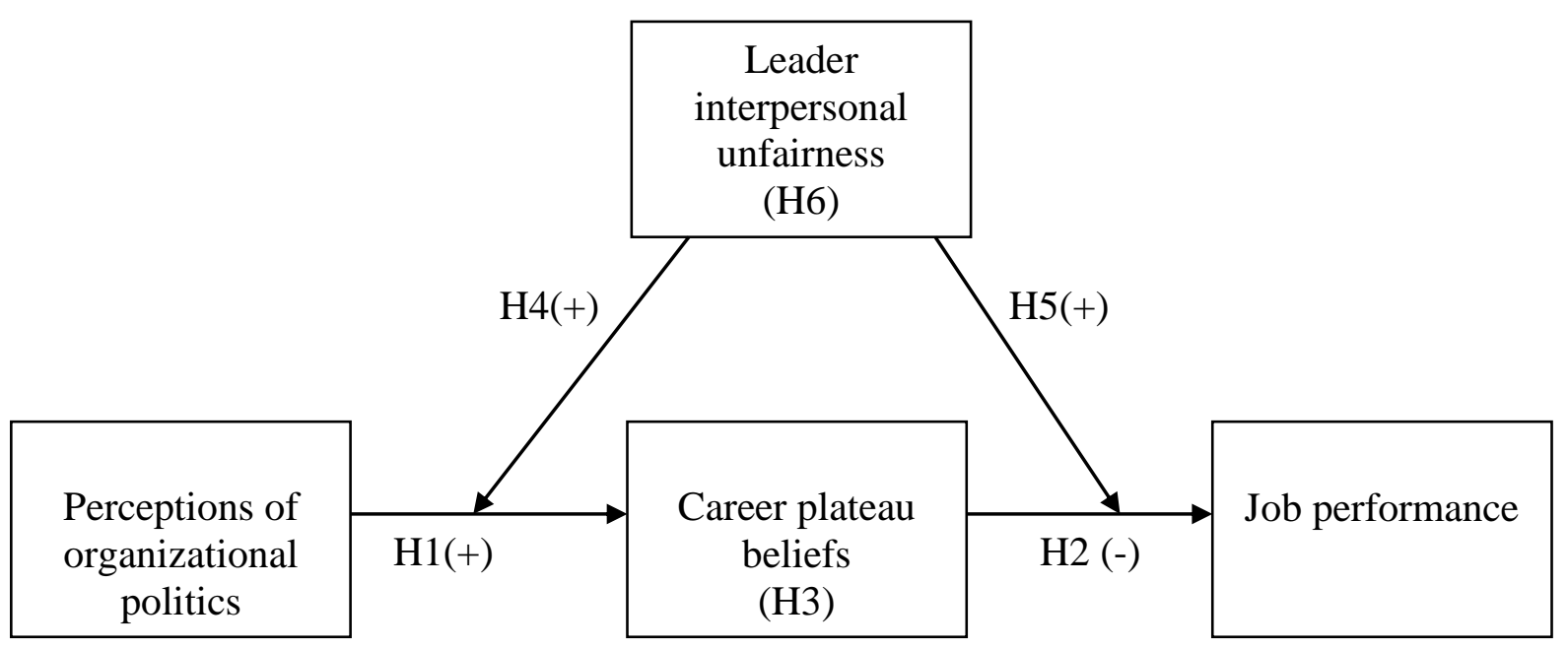

Notes: $\mathrm{H} 3$ represents the mediation of career plateau beliefs in the relationship between perceptions of organizational politics and job performance; H6 represents the moderated mediation effect by leader interpersonal unfairness on the indirect relationship between perceptions of organizational politics and job performance through career plateau beliefs. 
Figure 2: Moderating effect of leader interpersonal unfairness on the relationship between perceptions of organizational politics and career plateau beliefs

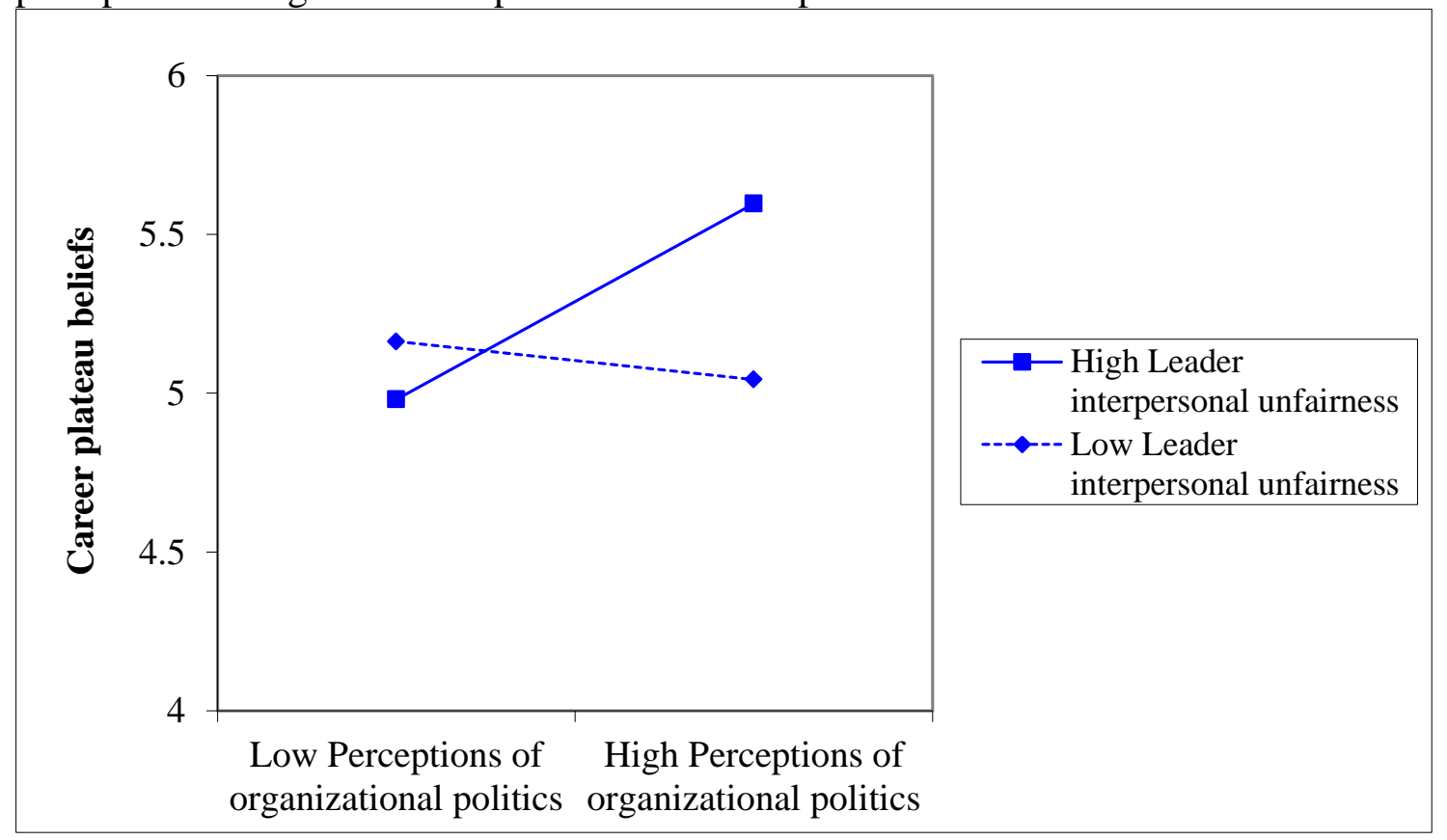

Figure 3: Moderating effect of leader interpersonal unfairness on the relationship between career plateau beliefs and job performance

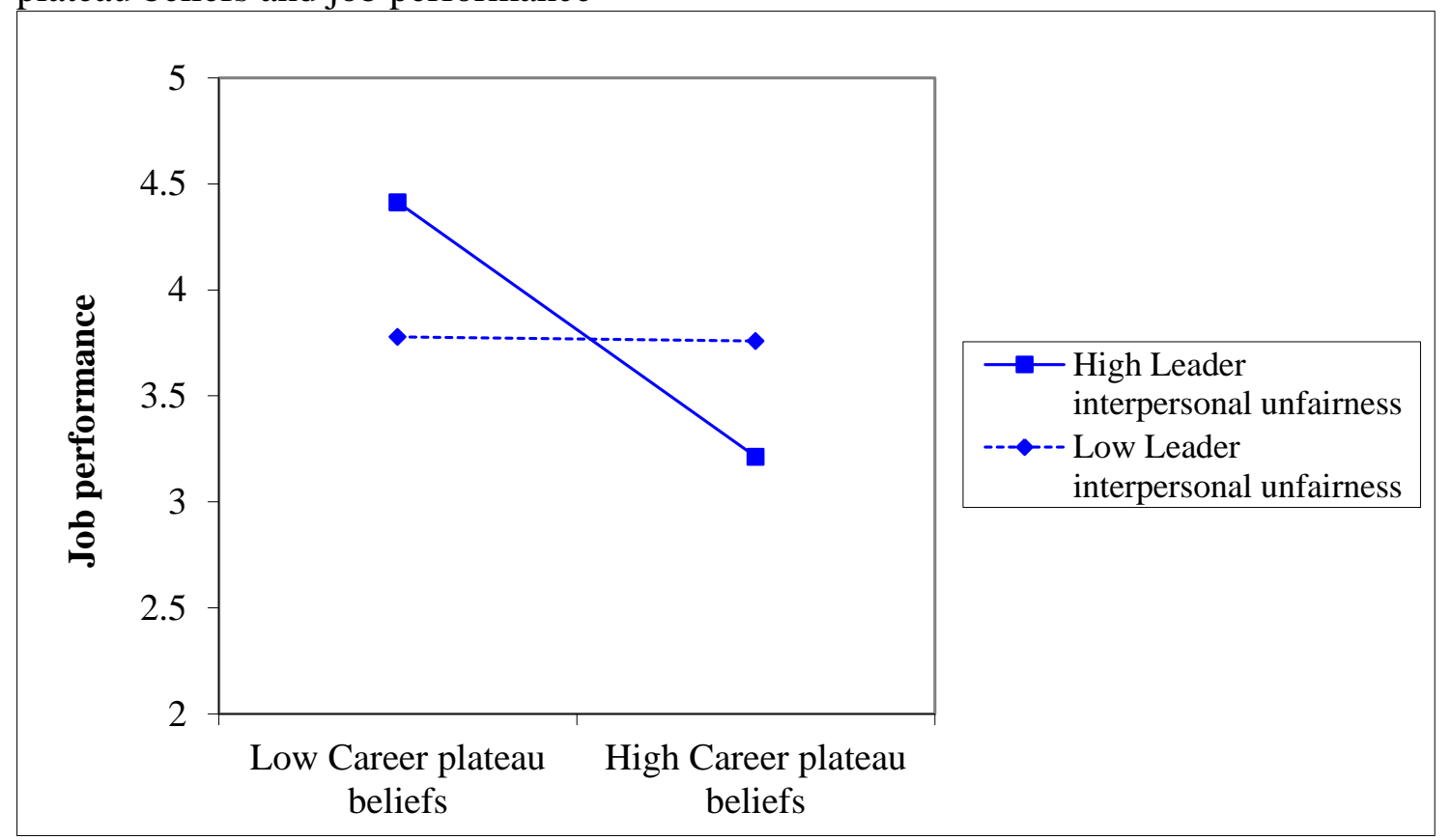


Table 1. Correlations and descriptive statistics

\begin{tabular}{lccccccc}
\hline & 1 & 2 & 3 & 4 & 5 & 6 & 7 \\
\hline $\begin{array}{l}\text { 1. Perceptions of } \\
\text { organizational politics }\end{array}$ & & & & & & & \\
2. Leader interpersonal & $.566^{* *}$ & & & & & & \\
unfairness & & & & & & & \\
3. Career plateau beliefs & $.283^{* *}$ & $.328^{* *}$ & & & & & \\
4. Job performance & $-.279^{* *}$ & $-.199^{* *}$ & $-.226^{* *}$ & & & & \\
5. Gender (1 = female) & -.017 & -.109 & $-.166^{*}$ & .036 & & & \\
6. Age & .097 & $.171^{* *}$ & .035 & .027 & $-.154^{*}$ & & \\
7. Organizational tenure & .055 & .083 & .071 & .011 & $-.199 * *$ & $.408^{* *}$ & \\
\hline$\quad$ Mean & 3.806 & 2.804 & 5.842 & 3.705 & 1.248 & 2.026 & 1.470 \\
\multicolumn{1}{c}{ Standard deviation } & 0.512 & 1.123 & 0.580 & 0.900 & 0.433 & 0.294 & 0.697 \\
\hline
\end{tabular}

Notes: $\mathrm{n}=230$.

$* p<.05 ; * * p<.01$.

Table 2. Regression results

\begin{tabular}{|c|c|c|c|c|c|c|}
\hline & \multicolumn{3}{|c|}{ Career plateau beliefs } & \multicolumn{3}{|c|}{ Job performance } \\
\hline & Model 1 & Model 2 & Model 3 & Model 4 & Model 5 & Model 6 \\
\hline Gender $(1=$ female $)$ & $-.213^{*}$ & $-.186^{*}$ & $-.177 *$ & .088 & .032 & .076 \\
\hline Age & -.012 & -.111 & -.132 & .093 & .166 & .155 \\
\hline Organizational tenure & .034 & .032 & .051 & .009 & .023 & .046 \\
\hline $\begin{array}{l}\text { Perceptions of organizational } \\
\text { politics }\end{array}$ & & $.171^{*}$ & .124 & & $-.394 * *$ & $-.297 *$ \\
\hline $\begin{array}{l}\text { Leader interpersonal } \\
\text { unfairness }\end{array}$ & & $.121 * *$ & $.093^{*}$ & & -.025 & .022 \\
\hline $\begin{array}{l}\text { Perceptions of organizational } \\
\text { politics } \times \text { Leader } \\
\text { interpersonal unfairness }\end{array}$ & & & $.184 * *$ & & & \\
\hline Career plateau beliefs & & & & & $-.238^{*}$ & $-.305 * *$ \\
\hline Career plateau beliefs $\times$ & & & & & & \\
\hline $\begin{array}{l}\text { Leader interpersonal } \\
\text { unfairness }\end{array}$ & & & & & & $-.295^{*}$ \\
\hline $\begin{array}{r}\mathrm{R}^{2} \\
\Delta \mathrm{R}^{2}\end{array}$ & .029 & $\begin{array}{c}.143 \\
.114 * * *\end{array}$ & $\begin{array}{c}.178 \\
.035^{* *}\end{array}$ & .002 & $\begin{array}{c}.106 \\
.103 * * *\end{array}$ & $\begin{array}{l}.126 \\
.020 *\end{array}$ \\
\hline
\end{tabular}

Notes: $\mathrm{n}=230$.

$* p<.05 ; * * p<.01 ; * * * p<.001$. 